\title{
Endovascular Treatment of Acute Ischemic Stroke
}

\section{급성 허혈성 뇌졸중의 혈관 내 치료}

\author{
Jun Hwee Kim, MD ${ }^{1}$ (D) Byung Moon Kim, MD²* \\ ${ }^{1}$ Department of Radiology, Yongin Severance Hospital, Yonsei University College of Medicine, \\ Yongin, Korea \\ ${ }^{2}$ Department of Radiology, Severance Hospital, Yonsei University College of Medicine, Seoul, Korea
}

Acute ischemic stroke is one of the leading causes of disability and death around the world, especially in developed countries. Since the introduction of the 2 nd generation devices, endovascular treatment of acute ischemic stroke has rapidly developed and is now considered to be a standard treatment. Here, we summarize the results of recent randomized clinical trials that have compared endovascular thrombectomy with conventional treatment for acute stroke and review the indications, current devices, and endovascular thrombectomy methods used.

Index terms Stroke, Acute; Mechanical Thrombolysis; Thrombectomy

\section{서론}

허혈성 뇌졸중은 그 이환율과 사망률이 크게 증가하고 있으며 선진국에서 주요한 사망원 인 중 하나로 보고되고 있다(1). 우리나라에서도 2014년 기준, 19세 이상 성인의 뇌졸중 유병 률은 $1.71 \%$ 이며, 매년 10 만 5 천명 가량의 환자가 발생하고 있다. 이 중 $76 \%$ 가 허혈성 뇌졸 중이며 나머지 24\%는 뇌내 출혈, 또는 지주막하 출혈의 형태로 발생하고 있다(2). 특히 75세 이상 인구의 뇌졸중 유병률은 54 세 이하의 인구에 비해 13 배나 높았으며 이는 급속도로 고 령화되고 있는 국내 인구구조를 고려한다면 유병률의 지속적인 증가를 예상할 수 있다.

대동맥의 급성 폐색에 의한 급성 허혈성 뇌졸중(acute ischemic stroke due to large vessel occlusion; 이하 급성 허혈성 뇌졸중) 환자에서 폐색된 혈관의 재개통(recanalization)은 환자의 예후에 가장 중요한 영향을 미치는 인자이다(3). 2014년까지 치료 효과가 입증된 유 일한 치료는 정맥 내 혈전용해제(intravenous recombinant tissue plasminogen activator; 이하 IV-tPA)의 투여였다. 그러나 IV-tPA 치료는 증상 발생 후 4.5시간 이내 환자에 대해 서만 적용이 가능하며, 더욱이 두개내 대동맥의 폐색에 의한 허혈성 뇌졸중에서는 그 효과 가 매우 제한적이었다(4). 위와 같은 이유로, 두개내 막힌 동맥 부위까지 직접 미세도관(microcatheter)을 삽입하여 약물로 혈전을 녹이거나, 기구를 삽입하여 혈전을 부수거나 제거
Received April 19, 2020

Revised May 4, 2020

Accepted May 16, 2020

${ }^{*}$ Corresponding author Byung Moon Kim, MD Department of Radiology, Severance Hospital, Yonsei University College of Medicine, 50-1 Yonsei-ro, Seodaemun-gu, Seoul 03722 Korea.

Tel 82-2-2228-7400

Fax 82-2-393-3035

E-mail bmoon21@hanmail.net

This is an Open Access article distributed under the terms of the Creative Commons Attribution Non-Commercial License (https://creativecommons.org/ licenses/by-nc/4.0) which permits unrestricted non-commercial use, distribution, and reproduction in any medium, provided the original work is properly cited.

\section{ORCID iDs}

Jun Hwee Kim (D) https:// orcid.org/0000-0002-0259-5795 Byung Moon Kim (D) https:// orcid.org/0000-0001-8593-6841 
하려는 혈관 내(endovascular) 재개통 치료법의 개발을 위한 많은 노력이 있었다. 하지만, 2013년 까지 발표된 3개의 무작위 배정 임상시험들에서 혈관 내 재개통 치료는 고식적 치료에 비해 우월 한 효과를 입증하지 못하였다(5-7).

그 후, 새로이 개발된 제2세대 혈전제거기구(stent retriever, 회수성스텐트)를 이용한 혈관 내 혈전제거술(endovascular thrombectomy; 이하 혈전제거술)이 이전에 사용된 혈전제거기구에 비해 훨씬 우월하다는 것이 2 개의 무작위 배정 임상시험에서 증명되었고 $(8,9)$, 드디어 전방 순환 계(anterior circulation) 급성 허혈성 뇌졸중에서 회수성스텐트를 이용한 혈전제거술과 고식적 치료법을 비교한 5개의 무작위 배정 임상시험의 성공이 ‘New England Journal of Medicine'에 2015년에 발표되었다. 이 연구들 모두에서 급성 허혈성 뇌졸중(acute ischemic stroke) 환자에서 혈전제거술이 고식적 치료에 비해 분명히 우월한 효과와 안전성을 보임이 입증되었다(10-14). 이 러한 결과를 바탕으로 혈전제거술이 광범위하게 사용되면서 IV-tPA 투여와 함께 또는 혈전제거술 단독으로 사용되는 경우가 급격히 증가하여, 현재는 전 세계에서 하나의 표준치료로서 자리 잡게 되었다. 더욱이 2018년에는 2개의 무작위 배정 임상시험에서 증상 발생 후 6 24시간 사이의 환자 에서도 뇌영상검사를 이용하여 적합한 환자를 선택할 경우에 혈전제거술이 고식적 치료에 비해 매우 큰 치료 효과를 보인다는 것이 입증되어 치료 적용 가능 시간을 획기적으로 확장시킬 수 있 었고, 이 결과는 최근 전 세계의 모든 허혈성 뇌졸중 치료 지침(guideline)에 반영되었다(11, 12).

이 종설에서는 먼저 허혈성 뇌졸중 치료 지침에 중대한 영향을 끼친 임상 연구들을(milestone clinical trials) 간략히 알아본 후, 급성 허혈성 뇌졸중 환자 치료에 있어서 혈전제거술의 적응증과 현재 사용되는 치료 기구 및 방법에 대해 소개하고자 한다.

\section{혈전제거술을 이용한 치료법의 무작위 배정 임상시험 결과}

최근까지 급성 허혈성 뇌졸중에서 정맥 내 혈전용해술이 유일한 치료법으로 인정받고 있었으 나, 증상 발생 후 4.5시간 이내에 치료를 시작해야 한다는 점과, 두개내(intracranial) 대동맥(large artery) 폐색에서의 낮은 재개통 성공률로 인해 그 한계가 명백했다. 따라서, 치료 가능 시간을 확 장하고 두개내 대동맥 폐색에서의 재개통 성공률을 높이기 위해 혈관 내 재개통 치료법에 대한 많 은 연구가 시도되었다. 그러나, 2013년까지 보고된 무작위 배정 임상시험들은 고식적 치료에 비해 혈전제거술의 이점을 증명하는 데에 실패하였다(5-7). 그 이유는 적극적인 영상 검사를 통해 혈관 내 치료에 적절한 환자군의 선별을 제대로 하지 못했다는 점과 함께 치료 방법에 있어서도 고식적 인 혈전용해제나 비효율적인 1세대 혈전제거기구를 주로 사용함으로써 재개통 성공률이 기대만 큼 높지 않았고, 재개통에 성공했을지라도 재개통까지 걸린 시간이 길었고, 두개내 출혈(intracranial hemorrhage) 같은 치료 합병증이 높았다는 것으로 설명할 수 있다.

그 후, 새로이 개발된 2세대 혈전제거기구인 회수성스텐트가 이전에 사용된 혈전제거기구에 비 해 훨씬 우월하다는 것이 2 개의 무작위 배정 임상시험에서 증명되었다 $(8,9)$. 따라서, 제 2 세대 혈전 제거기구인 회수성스텐트를 주로 사용하여 5 개의 무작위 배정 임상시험들이 진행되었고, 그 연구 들 모두에서 혈전제거술이 고식적인 치료에 비해 우월하다는 것이 입증되었다(10-14). 
Table 1. Comparison of Papulation and Sampling Frame among the Five Randomized Trials

\begin{tabular}{|c|c|c|c|c|c|}
\hline & MR CLEAN (10) & ESCAPE (11) & EXTEND IA (13) & SWIFT PRIME (12) & REVASCAT (14) \\
\hline No. of patients & 500 & 315 & 70 & 196 & 206 \\
\hline Age, years & $\geq 18$ & $\geq 18$ & $\geq 18$ & $18-85$ & $18-80$ \\
\hline NIHSS score & NA & $\geq 6$ & NA & $\geq 6$ & $\geq 6$ \\
\hline Time to randomization, hours & $<6$ & $<12$ & $<6$ & $<6$ & $<8$ \\
\hline Imaging tool & NECT/CTA & NECT/CTA & NECT/CTA/CTP & NECT/CTA/CTP & NECT/CTA \\
\hline Occlusion site & ICA, MCA M1, M2 & ICA, MCA M1 & ICA, MCA M1, M2 & ICA, MCAM1 & ICA, MCA M1 \\
\hline Imaging Inclusion criteria & NA & ASPECTS 6-10 & $\begin{array}{l}\text { CTP mismatch and } \\
\text { ischemic core }<70 \mathrm{~mL}\end{array}$ & $\begin{array}{l}\text { CTP or DWI (first } 72 \text { patients), } \\
\text { thereafter CT or } \\
\text { MR ASPECTS } 6-10\end{array}$ & ASPECTS 6-10 \\
\hline Recanalization success of EVT, \% & 75.4 & 72.4 & 86 & 88 & 65.7 \\
\hline \multicolumn{6}{|l|}{ mRS 0-2, \% } \\
\hline Control & 19.1 & 29 & 40 & 35 & 28 \\
\hline EVT & 32.6 & 53 & 71 & 60 & 44 \\
\hline
\end{tabular}

ASPECTS = Alberta Stroke Program Early Computed Tomography Score, CTA = computed tomography angiography, CTP = computed tomography perfusion study, DWI = diffusion weighted image, ESCAPE = Endovascular Treatment for Small Core and Anterior Circulation Proximal Occlusion with Emphasis on Minimizing CT to Recanalization Times, EVT = endovascular thrombectomy, EXTEND IA = Extending the Time for Thrombolysis in Emergency Neurological Deficits-Intra-Arterial, ICA = internal carotid artery, M1 = first segment of middle cerebral artery, M2 = second segment of middle cerebral artery, MCA = middle cerebral artery, MR CLEAN = Multicenter Randomized Clinical Trial of Endovascular Treatment for Acute Ischemic Stroke in the Netherlands, mRS = modified Rankin Scale score, NA = not applicable, NECT = non-enhanced computed tomography, NIHSS = National Institute of Health Stroke Scale, REVASCAT = Revascularization with Solitaire FR Device versus Best Medical Therapy in the Treatment of Acute Stroke Due to Anterior Circulation Large Vessel Occlusion Presenting within Eight Hours of Symptom Onset, SWIFT PRIME = Solitaire with the Intention for Thrombectomy as Primary Endovascular Treatment

위의 5 개의 임상 연구들의 대상자 선택 기준과 연구 방법을 Table 1 에 간략히 요약하였다.

먼저 가장 규모가 크고 첫 번째로 시험이 완료되었던 Multicenter Randomized Clinical Trial of Endovascular Treatment for Acute Ischemic Stroke in the Netherlands (MR CLEAN) 연구 에서 고식적 치료에 비해 혈전제거술을 받은 환자군은 90 일 후 양호한 예후(modified Rankin Scale score; 이하 mRS) 비율에서 유의하게 높았다(32.6\% vs. 19.1\%). 2년 후 시행한 mRS 평가에 서도 90일 후 결과와 거의 비슷한 비율을 보였다(10).

Endovascular Treatment for Small Core and Anterior Circulation Proximal Occlusion with Emphasis on Minimizing CT to Recanalization Times (ESCAPE) 시험은 증상 발생 12시 간 이내의 전방순환동맥 폐색 환자 316 명을 대상으로 기계적 혈전제거술의 효과를 비교하였다. 또한 최초 경색 영역이 큰 환자와 곁순환(collateral circulation)이 부족한 환자를 배제하고 시험 을 수행하였다. 그 결과 90일 후 평가에서 고식적 치료에 비해 상당히 높은 성과를 보였고(mRS 0-2, 53\% vs. 29\%), 유의하게 낮은 사망률을 보였다(10\% vs. 19\%). 또한 80세 이상의 연령, 신경 학적 중증도가 높을 경우(severe stroke), IV-tPA 치료를 받지 않은 환자군에 대한 하위 그룹 연구 에서도 혈전제거술을 시행하는 것이 유용함을 보여주었다(11).

Solitaire with the Intention for Thrombectomy as Primary Endovascular Treatment (SWIFT PRIME) 시험은 18 80세 사이의, 증상 발생 후 6시간 이내의 전방순환동맥 폐색 환자 196 명을 대상으로 IV-tPA 후 회수성스텐트를 이용한 혈전제거술과 IV-tPA만 사용한 치료를 비교하였 
고, 역시 유의한 90일 후 혈전제거술 치료군이 우월한 예후를 보였다(mRS 0-2, 60\% vs. 35\%) (12).

Extending the Time for Thrombolysis in Emergency Neurological Deficits-Intra-Arterial (EXTEND-IA) 시험은 70명의 급성 허혈성 뇌졸중 환자를 무작위로 IV-tPA 후 회수성스텐트를 이 용한 혈전제거술과 IV-tPA만으로 치료한 그룹으로 나누어 배정하여 결과를 비교하였다. 뇌관류영 상에서 살릴 수 있는 허혈성 뇌조직(ischemic penumbra)이 없거나 완전히 뇌경색이 진행된 뇌 조직의 용적이 $70 \mathrm{~mL}$ 이상인 환자를 배제하고 시험을 시행하였으며 역시 90 일 후 혈전제거술 치 료군이 우월한 예후를 보였다(mRS 0-2, 71\% vs. 40\%) (13).

Revascularization with Solitaire FR Device versus Best Medical Therapy in the Treatment of Acute Stroke Due to Anterior Circulation Large Vessel Occlusion Presenting within Eight Hours of Symptom Onset (REVASCAT) 시험은 증상 발생 후 8시간 이내의 급성 허혈성 뇌졸중 환자 206명을 대상으로 고식적 치료와 혈전제거술을 비교하였다. 90일 후 mRS 0-2 비율은 44\% vs. $28 \%$ 로 혈전제거술에서 유의하게 높았으며, 추적관찰에서 뇌내 출혈 또는 사망률은 두 그룹 간 유 의하게 차이를 보이지 않았다(14).

위에서 기술한 대로 5 개의 연구 결과를 바탕으로 하여 혈전제거술은 급성 허혈성 뇌졸중의 표 준 치료법 중 하나가 되었다. 그럼에도 불구하고, 혈전제거술의 적용 가능 시간이 6시간에서 12 시 간 이내로 각 연구마다 달랐고, 그중 3 개의 연구에서는 6 시간 이내의 환자에서만 치료가 적용되었 기 때문에, 이 연구들을 배경으로 마련된 치료 지침에서는 허혈성 뇌졸중 발생 후 6 시간 이내의 환 자만이 혈전제거술의 적응증이 되었다 $(15,16)$.

위의 5 개의 연구들에서 공통적인 성공 요인을 분석해 보면 첫째, 적극적으로 비침습적 뇌혈관영 상검사(CT 또는 MR 뇌혈관조영술)를 이용하여 혈전제거술에 적절한 환자를 선택하였고(right patient selection), 둘째, 이미 무작위 배정 임상시험에서 1 세대 혈전제거기구에 비해 훨씬 효과적 이고 안전하다고 증명된 2세대 혈전제거기구인 회수성스텐트를 주로 사용하였으며(use of effective device), 마지막으로 환자 도착 후 혈전제거치료 시작까지의 시간을 효율적으로 단축했다는 점이다(optimization of workflow).

이후 위의 연구에 포함된 1287 명의 환자들의 개별(individual) 데이터를 대상으로 한 메타분석 에서, 치료 효과와 증상 발생 후 재개통까지 걸린 시간과의 관계에 있어서, 재개통이 1 시간 지연될 때마다 약 $6.7 \%$ 씩 신경학적 결손이 악화되며 3개월 후 양호한 예후의 가능성이 $5.2 \%$ 씩 감소하는 것으로 나타났다. 이와 같은 결과들을 바탕으로 혈전제거술의 치료 가능 시간(treatment time window)을 증상 발생 후 약 7.3시간으로 제시하였다(17). 그러나, 실제 임상에서 혈전제거술을 시 행했을 때, 증상 발생 후 상당한 시간이 지난 환자에서도 좋은 결과를 보인다는 연구들이 많이 보 고되고 있었고, 따라서, 시간이 지나도 회복 가능한 뇌조직(salvageable brain tissue, penumbra) 영역에 대한 관심이 높아졌다. 실제로 MRI profile and response to endovascular reperfusion after stroke (DEFUSE-2)를 비롯한 여러 연구들에서 표적 불일치(target mismatch)가 있는 환자 를 대상으로 혈전제거술을 시행했을 때, 증상 발생 6시간 이후에서도 6시간 이내에 시행 받은 환 자군과 임상적 예후에서 큰 차이가 없음을 보여주었다(18-20).

따라서, 혈전제거술의 치료 적용 가능 시간을(time window) 확장시키고자 하는 연구들이 진행 
Table 2. Comparison of Population and Sampling Frame between the DAWN and DEFUSE-3 Trials

\begin{tabular}{|c|c|c|}
\hline & DAWN (21) & DEFUSE-3 (22) \\
\hline No. of patients & 206 & 182 \\
\hline Age, years & $\geq 18$ & $18-90$ \\
\hline NIHSS & $\geq 10$ & $\geq 6$ \\
\hline Pre-stroke mRS & 0 or 1 & $0-2$ \\
\hline Occlusion site & ICA, M1 & ICA, M1 \\
\hline Imaging tool & CTA or MRA + CTP or MRP & CTA or MRA + CTP or MRP \\
\hline $\begin{array}{l}\text { Definition of infarct core and penumbra on } \\
\text { perfusion study with RAPID software }\end{array}$ & $\begin{array}{l}\text { Infarct core, } \mathrm{CBF}<30 \mathrm{~mL} \text { penumbra, } \\
\text { Tmax }>6 \mathrm{sec}\end{array}$ & $\begin{array}{l}\text { Infarct core, } \mathrm{CBF}<30 \mathrm{~mL} \text { penumbra, } \\
\text { Tmax }>6 \mathrm{sec}\end{array}$ \\
\hline Inclusion criteria & $\begin{array}{l}\text { A. Age } \geq 80 \mathrm{y} \\
\text { 1. NIHSS } \geq 10 \text { and core }<21 \mathrm{~mL} \\
\text { B. Age }<80 \mathrm{y} \\
\text { 2. NIHSS } \geq 10 \text { and core }<31 \mathrm{~mL} \\
\text { 3. NIHSS } \geq 20 \text { and core }<51 \mathrm{~mL}\end{array}$ & $\begin{array}{l}\text { Meet the both of followings; } \\
\text { 1. Target mismatch profile: ratio of penumbra/ } \\
\text { core } \geq 1.8 \text { or absolute penumbra volume } \\
\geq 15 \mathrm{~mL} \\
\text { 2. Infarct core }<70 \mathrm{~mL}\end{array}$ \\
\hline Recanalization success of EVT, \% & 84 & 76 \\
\hline \multicolumn{3}{|l|}{ mRS 0-2, \% } \\
\hline Control & 13.1 & 17 \\
\hline EVT & 35.5 & 45 \\
\hline
\end{tabular}

$\mathrm{CBF}=$ cerebral blood flow, CTA, computed tomography angiography, CTP = computed tomography perfusion study, DAWN = DWI or CTP Assessment with Clinical Mismatch in the Triage of Wake-up and Late Presenting Strokes Undergoing Neurointervention with Trevo, DEFUSE-3 = Endovascular Therapy Following Imaging Evaluation for Ischemic Stroke, EVT = endovascular thrombectomy, ICA = internal carotid artery, M1 = first segment of middle cerebral artery, MRA = MR angiography, MRP = MR perfusion, $\mathrm{mRS}=$ modified Rankin Scale score, NIHSS = National Institute of Health Stroke Scale

되었고, 드디어 2018년 치료 가능 시간을 6시간 이후로 확장한 2개의 무작위 배정 임상시험이 발 표되었다(21, 22). 그 연구들의 대상자 선택 기준과 연구 방법은 Table 2에 요약하였다.

그중 DWI or CTP Assessment with Clinical Mismatch in the Triage of Wake-up and Late Presenting Strokes Undergoing Neurointervention with Trevo (이하 DAWN) 연구에서는 마지 막 정상 확인 후 6 24시간까지 경과된 급성 허혈성 뇌졸중 환자 206명을 대상으로 나이, 뇌졸중의 중증도, 뇌관류영상을 통한 표적 불일치 부위의 부피를 기준으로 하여 환자를 선택했을 때 혈전제 거술의 효과를 입증하였다. 약 84\%의 환자에서 재개통에 성공하였고, 90 일 후 mRS 0-2 비율은 49\% vs. $13 \%$ 로 혈전제거술이 우세하였으며 사망률과 뇌내 출혈 발생은 치료군 간에 차이가 없었 다. 특히 DAWN 시험의 경우 90일째 utility weighted mRS라는 평가지표를 도입하여 보다 환자 의 기능적 독립성을 보다 잘 평가하고자 하였고 이 역시 치료군 vs. 대조군이 5.5 vs. 3.4의 수치를 보여 기계적 혈전제거술의 우월성을 보여주었다. 등록된 환자들 중 뇌경색의 부피, 나이, 내원 당 시 National Institute of Health Stroke Scale (이하 NIHSS) 점수, 증상 발생 후 무작위 배정 전까 지의 시간 등을 기준으로 한 하위 그룹 분석에서도 기계적 혈전제거술은 하위 그룹 분류에 상관없 이 효과가 있는 것으로 나타났다(21).

Endovascular Therapy Following Imaging Evaluation for Ischemic Stroke (DEFUSE-3) 시 험에서도 마찬가지로 마지막 정상 확인 후 16 시간까지 경과된 급성 허혈성 뇌졸중 환자 182 명을 대상으로 하여 90일 후 mRS 0-2 달성 비율이 45\% vs. $17 \%$ 로 혈전제거술의 효과를 보여주었다. 
90일 이내 사망률은 대조군이 치료군에 비해 유의하게 높았고, 심각한 이상 반응과 뇌내 출혈의 발생은 그룹 간 차이를 보이지 않았다. 증상 발생 후 무작위 배정까지의 시간을 기준으로 나눈 하 위 그룹 분석에서는 증상 발생 후 9 시간, 또는 12 시간 이후에 내원한 환자군 모두에서 기계적 혈전 제거술의 시행이 대조군에 비해 90일 후 기능적 독립성 달성이 우월함을 보여주었다. 또한 뇌경색 의 부피, 나이, 내원 당시 NIHSS 점수, 동맥 폐색의 위치에 따른 하위 그룹 분석에서도 일관되게 기계적 혈전제거술이 우월함을 제시하였다(22).

\section{혈전제거술을 위한 환자군의 선택}

대한뇌졸중학회와 대한신경중재치료의학회의 합의로 2019년에 개정된 급성 허혈성 뇌졸중의 진료 지침을 참고하여 혈전제거술의 적응증과 필요한 검사를 요약하면 다음과 같다(23).

1) 허혈성 뇌졸중 발생 후 6시간 이내의 환자로 그 원인으로 두개내 대동맥의 폐색이 뇌혈관영 상(CT 또는 $\mathrm{MR}$ 혈관조영술)에서 확인된 환자

- 두개내 대동맥은 전방 순환계(anterior circulation)에서는 두개내 내경동맥(internal carotid artery), 중뇌동맥(middle cerebral artery)의 첫 번째 부위(M1 segment) 또는 두 번째 부위 근위 부(M2 proximal segment)를 의미하고, 후방 순환계(posterior circulation)에서는 두개내 척추 동맥(vertebral artery V4 segment), 기저동맥(basilar artery), 후대뇌동맥(posterior cerebral artery) 첫 번째 부위(P1 segment)를 의미한다.

2) 허혈성 뇌졸중 발생 후 6 24시간 사이의 환자에서는, 다중 뇌영상기법(multimodal neuroimaging)에서 완전 뇌경색(infarct core)으로 진행되지 않은 허혈성 뇌조직(ischemic penum$\mathrm{bra})$ 의 크기가 충분히 크다고 판단된 경우

3) 혈전제거술을 위해 필수적인 영상검사는 다음과 같다.

- 모든 환자에서 뇌출혈 여부를 진단하기 위하여 비조영증강(non-enhanced) CT 또는 MR 영상 검사

- 모든 환자에서 두개내 대동맥 폐색을 진단하기 위하여 CT 또는 MR 혈관조영술

- 뇌졸중 발생 후 6 24시간 사이의 환자에서는 다중 뇌영상기법(multimodal neuroimaging). 여기서 다중 뇌영상기법은 뇌관류영상(CT/MR brain perfusion imaging)과 다중시기 CT 혈관조 영술(multi-phase CT angiography)을 의미한다.

혈관 내 혈전제거술의 적응증에 있어서 변화되고 있는 점은, 이전의 혈전제거술에 적합한 환자 의 선택에서는 증상 발생 후 경과한 시간이 환자 선택의 절대적 기준이었다면, 최근에는 발달된 다중 뇌영상검사 기법을 이용하여 판단했을 때, 혈전제거술로 재개통시켰을 때 기능이 회복 가능 한 허혈성 뇌조직(penumbra)이 얼마나 존재하는지가 판단 기준에 중요한 요인이 되었다. 그 결 과로 치료 가능 시간(treatment time window)을 6시간에서 24시간으로 연장시켰고, 앞으로는 24 시간 이상으로 더욱 연장될 것으로 예상된다.

한편, 후방 순환계에서의 급성 동맥 폐색으로 인한 허혈성 뇌졸중에서는 혈전제거술의 효과가 
아직까지 무작위 배정 임상시험으로 증명되지 못했다. 최근에 각광받고 있는 뇌관류영상을 통한 환자군의 선택 역시, 후방 순환계에서의 적용에는 제한점이 분명하다. 그러나 몇몇 후향적 연구나 관찰 연구에서 기저동맥과 척추동맥의 폐색 역시, 혈전제거술로 치료했을 때 약 30 40\%의 환자 에서 좋은 임상적 예후를 보였고, 약 $30 \%$ 미만의 사망률을 보였다 $(24,25)$. 반면에 IV-tPA만을 사 용한 후방 순환 폐색 환자에서는 약 22\%만이 좋은 임상적 예후를 보였고, 사망률은 $50 \%$ 정도로 보고되었다(26). 더욱이, 후방 순환계 폐색으로 인한 허혈성 뇌졸중의 예후가 매우 안 좋은 점을 고려하면, 후방 순환계에서도 혈전제거술이 환자의 예후를 향상시킬 가능성은 상당히 크다고 판 단된다. 이와 같은 연구를 바탕으로 위에 기술된 것처럼, 우리나라의 2019년 개정 진료지침에서도 후방 순환계 대동맥 폐색 환자에서도 혈전제거술을 시행을 권고하고 있다(23).

\section{혈관 내 혈전제거술의 준비와 시행}

\section{혈전제거술의 준비}

혈전제거술 준비에 있어서 가장 중요하게 고려해야 할 사항 중 하나는 환자가 병원에 도착하면 가능한 빨리 치료를 시작해야(optimization of in-hospital workflow) 한다는 것에 초점을 맞춰야 한다는 점이다. 이를 위해 우리나라에서도 대한뇌졸중학회와 대한신경중재치료의학회의 협동 작 업으로 병원 도착부터 혈전제거술 시행까지의 워크플로(workflow) 개선을 위한 지침을 발표하였 는데 이를 아래에 요약하였다(27).

1) 병원 도착에서 혈관조영실까지 시기(hospital arrival to angiography suite phase)

- 허혈성 뇌졸중이 의심되는 환자가 병원에 도착하면 빠른 검사를 위해 바로 CT 촬영실로 이송 을 권장한다.

- 허혈성 뇌졸중이 의심되는 환자가 병원에 도착하면 당일 혈전제거술 치료에 관여하는 모든 사 람에게 “사전 공지(warming call)”가 갈 수 있도록 권장한다.

- 기존의 신장질환(known kidney disease)이 없는 환자에서는 조영제 사용을 주저하지 말고 $\mathrm{CT}$ 혈관조영술 또는 뇌혈관관류영상을 바로 시행할 것을 권장한다.

- 환자 또는 환자의 법률적 대리자에게 치료에 대한 동의서를 받을 수 없는 경우에는, 혈전제거 치료에 직접적으로 관여하지 않는 다른 의사에게 동의서를 받아 치료를 진행할 것을 권장한다.

- IV-tPA 치료의 적응증이 될 경우에는 CT 촬영실에서 정맥 내 투여를 시작하고, CT 혈관조영술 에서 두개내 대동맥 폐색이 확인된 경우, CT 촬영실에서 바로 혈관조영실로 이송을 권장한다.

2) 빠른 치료 시작을 위한 혈관조영실에서의 준비

- 가능하면 혈전제거술을 위해 기구 세트(customized kit)를 미리 준비해 놓는 것을 권장한다 (Fig. 1).

- 치료를 위해 꼭 필요하지 않다면, 서혜부 면도, 요로관 삽입, 기관 삽입, 동맥관 삽입 등은 빠른 치료 시작을 위해 생략할 것을 권장한다.

- 같은 이유로 치료를 위한 전신마취는 권장되지 않는다. 
Fig. 1. Customized kit for the endovascular treatment of acute stroke. Adapted from Kim et al. Korean J Radiol 2018;19:838-848 (27).

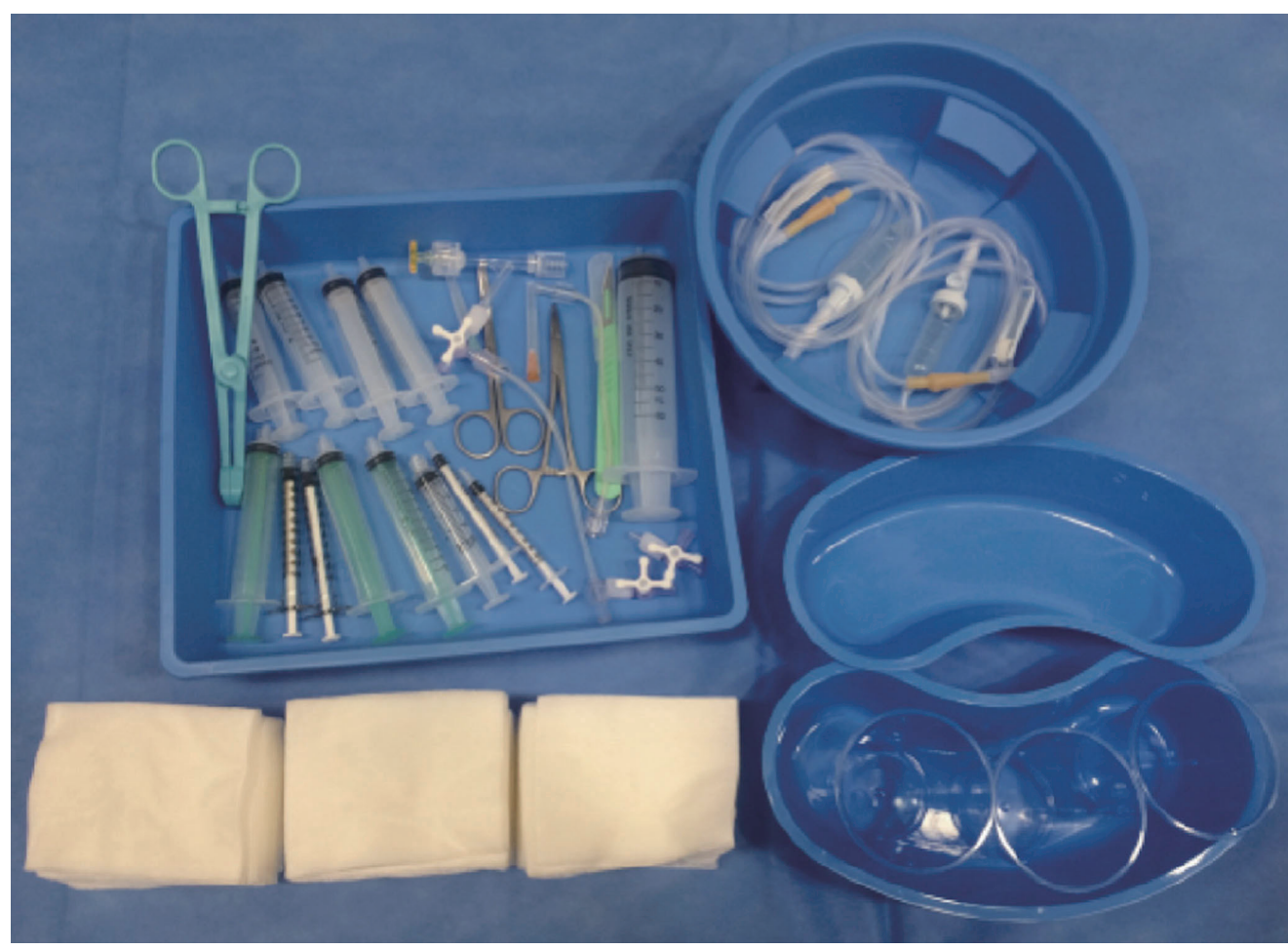

\section{혈관 내 혈전제거술}

현재 유용성이 인정되어 사용되고 있는 혈관 내 혈전제거기구는 크게 회수성스텐트 계열과 혈 전 흡입용(aspiration) 도관(catheter) 두 가지로 분류할 수 있다.

앞서 기술한, 혈전제거술의 효과를 확립한 5 개의 무작위 배정 임상시험에서 회수성스텐트를 주 로 이용하여 시술을 받은 환자군은 전체의 $80 \%$ 이상이었다. 이 중 성공적인 혈관 재개통(modified Tissue Thrombolysis In Cerebral Ischemia; mTICI, 2b-3)을 보인 비율은 58 88\%였으며, 3 개월 후 양호한 예후(mRS, 0 2)를 보인 비율은 53 71\%로 고식적인 정맥 내 혈전 용해 치료나 1 세대 혈전제거기구에 비해 압도적인 성과를 보여주었다. 또한 시술로 인한 뇌내 출혈 발생 확률 역시 0 7.7\%로 고식적 혈전용해술에 비해 높지 않았다.

회수성스텐트를 이용한 시술 과정을 아래에 단계별로 요약하였다(Fig. 2) (28).

- $6 \mathrm{~F}$ 이상의 유도도관이나 $8 \mathrm{~F}$ 이상의 풍선유도도관(balloon guide catheter)을 혈관폐색이 있 는 부위의 내경동맥에 가능한 말단부에 위치시킨다.

- 혈관 폐색부위를 혈관조영술을 통해 확인한다(Fig. 2A).

- 미세유도철사(microwire)와 미세도관을 이용하여 폐색부위를 통과한 후, 미세도관을 통해 조 영제를 투입하여 혈관폐색의 범위를 확인한다(Fig. 2B, C).

- 미세도관을 통해 회수성스텐트를 삽입한 후, 회수성스텐트가 뇌혈관의 폐색 부위에 놓이도록 미세도관을 벗겨서 회수성스텐트가 혈관의 막힌 부위를 전장에 걸쳐 위치하게 한다(Fig. 2D, E).

- 회수성스텐트와 혈전이 충분히 엮이도록(integrating) 수 분간 기다린 후, 풍선유도도관의 풍 
Fig. 2. Endovascular thrombectomy for acute stroke with a stent retriever.

A. Left internal carotid angiogram shows occlusion at the left middle cerebral artery M1 segment.

B. Microcatheter is navigated through the occlusion site to the left M2 segment using a microwire.

C. Schema of the microcatheter navigation. Thick arrow, thin arrow, and dotted arrow indicate occluding thrombus, micro-catheter tip, and micro-guidewire, respectively.

D. Spot image during deployment of the stent retriever. The red dashed arrow indicates the stent retriever distal marker.

E. Schema of the deployment of the stent retriever. Red arrow indicates the clot engaged in stent retriever. Red dotted arrow indicates the distal markers of stent retriever at the inferior branch of the left middle cerebral artery.

F. Spot image during the retrieval of the stent retriever under the inflation of the BGC. The red dotted arrow indicates the stent retriever distal marker. G. Schema of the retrieval of the stent retriever. Black arrow indicates the micro-catheter tip. Red dotted arrow indicates the distal marker of stent retriever.

H. Photography of the removed clot which is integrated with the stent retriever.

I. A control angiogram after the clot removal shows complete recanalization of the left middle cerebral artery. $\mathrm{BGC}=$ balloon guide catheter

Adapted from Park. Springer;2017. p.191-211 (28).
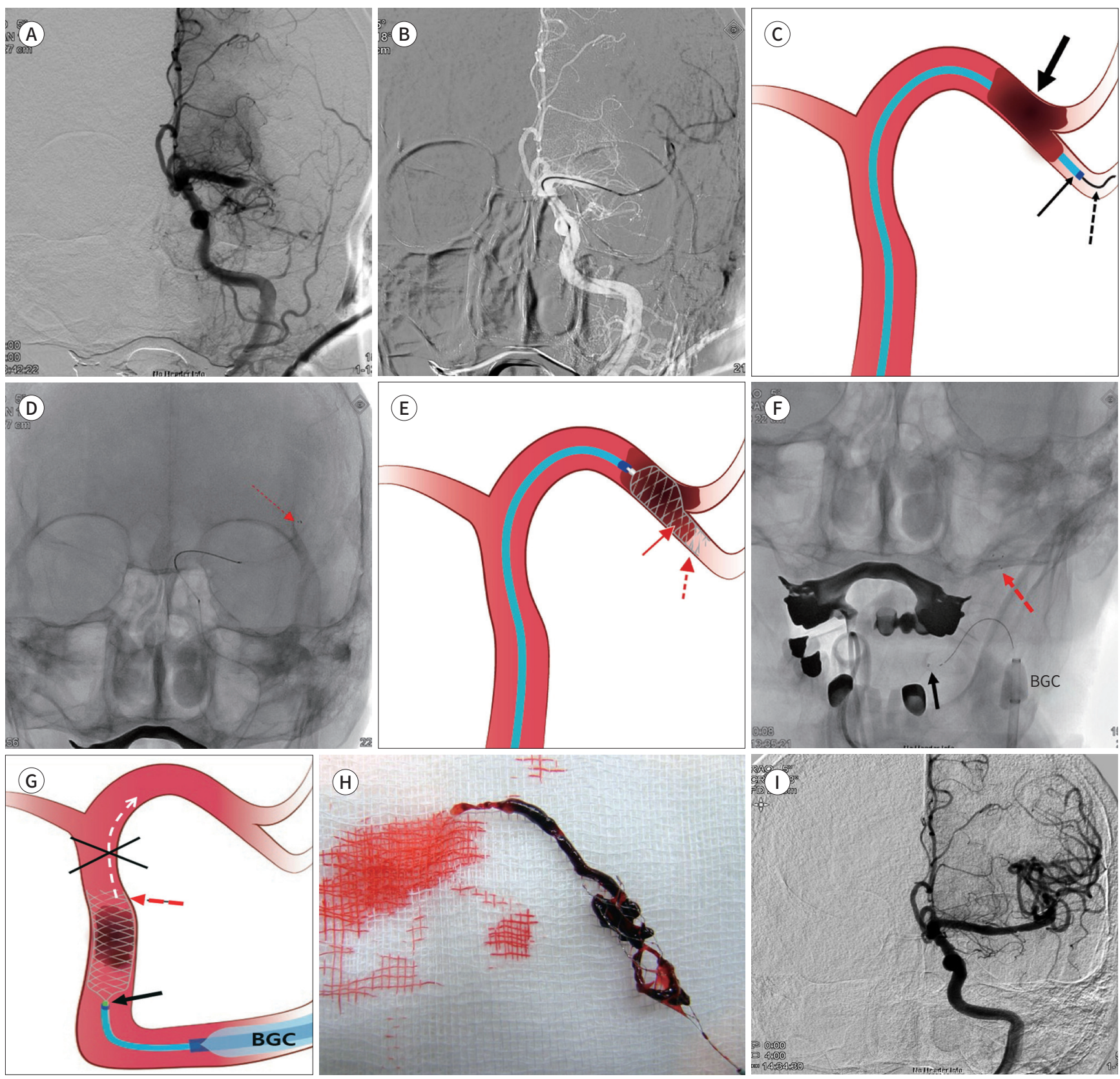
선을 부풀려서 모동맥으로부터의 혈류를 차단하여(flow arrest) 회수성스텐트를 제거할 때, 스텐 트와 엮여 있던 혈전이 떨어져서 다시 말단부로 이동하는 것을 방지한다.

- 회수성스텐트를 조심스럽게 당겨 혈전과 함께 체외로 제거한다. 이때 펌프나 큰 주사기를 이 용하여 풍선유도도관에 충분한 음압을 걸어 혈전이 말단부로 색전되는 것을 방지한다(Fig. $2 \mathrm{~F}, \mathrm{G}$ ).

- 회수성스텐트의 완전 제거 후에는 풍선을 자발적으로 수축시키면서(spontaneous deflation) 깨끗한(fresh) 피가 나올 때까지 계속 풍선유도도관을 통해 흡입하여 모혈관에 남아 있을 수 있는 혈전을 제거한다.

- 깨끗한 피가 나오는 것을 확인 후, 회수성스텐트와 흡인된 피에서 혈전을 확인한다(Fig. 2H).

- 혈관조영술을 시행하여 재개통이 성공했는지 확인한다(Fig. 2I).

- 재개통이 성공하지 못했으면, 위의 시술 순서를 반복한다.

최근에는 더 높은 재개통 효과를 목표로 다양한 디자인의 회수성스텐트가 개발되어, 이들을 이 용한 연구 결과가 지속적으로 발표되고 있다(29-31). 그러나, 기본적인 혈전제거의 원리나 방법은 위에 기술한 방법에서 크게 다르지 않다.

현재까지 성공적으로 발표된 혈전제거술의 무작위 배정 임상시험들 대부분에서 회수성스텐트 를 첫 번째 기구로 사용하여 혈전제거술을 시행하였으므로, 2019년까지 발표된 치료지침에서는 회수성스텐트를 첫 번째 치료 기구로 사용할 것을 권장하고 있다. 그러나, 최근에는 흡인에 효과 적일 만큼 충분한 직경을 가지면서도 복잡한 두개내 동맥의 주행을 따라갈 수 있을 만큼 부드럽고 유연한 흡인용 도관들이 많이 개발되었다. 따라서, 개선된 흡인용 도관을 막힌 혈관 부위까지 진 입시켜서, 혈전과 직접 접촉시킨 후 흡인을 통해 혈전을 제거하는 방법을 이용하는 비율도 점점 증가하고 있다. 즉, 흡인용 도관(aspiration catheter)을 삽입하여 두개내 혈관의 폐색부위까지 진 입시킨 후 혈전과 도관의 말단부가 충분이 접촉하도록 위치시킨 후, $30 ~ 50 \mathrm{~mL}$ 용량의 주사기를 연결하여 수동으로 당기거나, 흡인용 펌프를 연결하여 혈전을 흡인하여 제거하는 방식이 일반적 이다(Fig. 3). 흡인용 도관을 이용한 혈전제거술의 경우 회수성스텐트에 비해 상대적으로 필요한 기구의 개수가 적게 필요하고, 시술의 단계가 단순화되어 혈관재개통에 소요되는 시간이 단축될 수 있고, 비용 면에서 유리하다는 의견도 있다(32). 최근에는 이러한 흡인용 도관과 회수성스텐트 중 어느 것이 더 효과적인가에 대한 무작위 배정 임상시험들도 진행되었다. 2017년에 발표된 무작 위 배정 임상시험에서는 회수성스텐트의 사용과 흡인용 도관을 이용한 혈전제거술을 비교하였 고, 각각 재개통 성공률( $86.2 \%$ vs. $85.4 \%)$ 과 양호한 임상 예후의 비율(50.0\% vs. $45.3 \%)$ 에서 유의 할 만한 차이를 보이지 않았다(33). 2019년에는 보다 개선된 흡인용 도관을 이용한 연구에서 흡인 용 도관을 이용한 혈전제거술이 $92 \%$ 의 재개통 성공률과 $52 \%$ 의 양호한 임상예후를 보여, 회수성 스텐트를 사용한 방법에 비해 열등하지 않음을 보고하였다(34).

실제 치료에서는 일반적으로 시술자의 선호도와 숙련도에 따라, 위의 두 가지 종류의 기구들 중 하나를 선택하여 먼저 혈전제거술을 시도하고, 몇 번의 시도에도 실패할 경우에는 다른 기구를 사 용하거나, 두 종류의 기구를 동시에 사용하여 추가적인 시도를 하게 된다. 그러나, 최근에는 처음 부터 두 종류의 기구를 동시에 사용하는 것이 재개통 성공률을 높인다는 보고도 있다 $(35,36)$. 두 가지 기구를 동시에 사용하는 것이 성공률을 높인다는 이론적 배경은 다음과 같다. 첫째, 내경동 
Fig. 3. Endovascular thrombectomy for acute stroke with an aspiration catheter.

A. Left internal carotid angiogram shows occlusion of the left middle cerebral artery M1 orifice.

B. Spot image shows a large-bore during navigation aspiration catheter (arrow) over the microcatheter and a microwire.

C. Spot image showing the aspiration catheter (arrow) contacting the occluded clot.

D. Photograph of the removed clot. The right photograph shows the clot engaged in the aspiration catheter, and the left photograph shows the clot removed from the catheter. The dashed line indicates the segment of the clot inside the catheter.

E. Control angiogram immediately after contact aspiration thrombectomy shows complete recanalization.
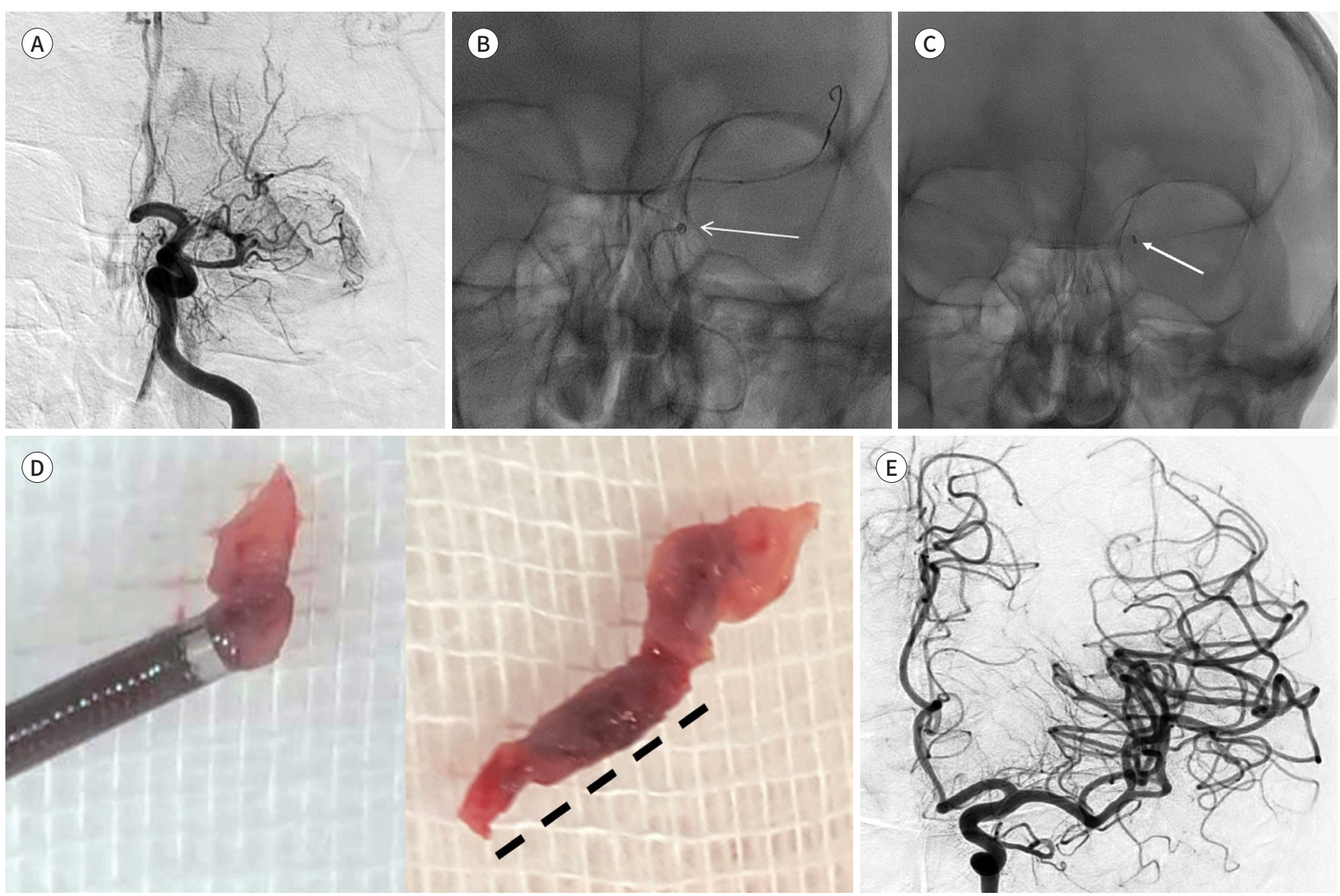

맥이 해부학적으로 구불거림이 심할 경우, 풍선유도도관이 충분한 위치까지 진입하지 못해 혈전 제거술 중에 풍선유도도관을 위한 흡인이 비효과적이어서 혈전제거기구를 회수하는 중에 말단부 색전의 가능성이 높아지며 둘째로, 두개내 혈관이 굴곡이 심하거나 협착이 있을 경우에는, 흡인용 도관과 혈전과의 접촉이 충분치 못하거나 회수성스텐트를 당기는 힘의 방향이 달라져 혈관이 꺾 이는 부위에서 회수성스텐트가 찌그러지면서 혈전이 빠져나갈 수 있어 혈전의 제거가 비효과적 일 수 있다. 이 같은 경우에서 흡인용 도관과 회수성스텐트를 동시에 사용할 경우에 서로 상보적 으로 작용하여, 보다 효율적으로 혈전제거에 성공할 수 있다는 것이다(37, 38).

앞에서 기술한 모든 방법에서 일반적인 유도도관보다는 풍선유도도관의 동시 사용이 권장되고 있다. 즉, 회수성스텐트를 당기거나 흡인용 도관으로 흡인을 시행할 때에 풍선유도도관의 말단부 에 장착된 풍선을 팽창시켜 모동맥의 혈류를 차단하고, 그 상태에서 혈전제거술을 시행할 것을 권 장한다. 그 이유는 모동맥의 혈류를 차단하고 혈전제거 중 모동맥에서 음압을 걸어 시술 도중 혈 전을 포획한 기구에서 혈전을 놓치거나 혈전이 분쇄됨으로써 생기는 원위부나 다른 부위 혈관으 
로의 새로운 색전의 가능성을 줄일 수 있다는 것이 이론적 근거이다. 실제로 이러한 방법을 통해 혈전제거가 보다 용이하고, 재개통까지의 기구 통과 횟수를 줄일 수 있을 뿐만 아니라 첫 번째 시 도에서 성공할 가능성이 높고, 그 결과로 임상예후도 개선시킨다고 보고되었다(39-42). 특히 혈전 의 양이 많거나 보다 긴 구역의 폐색이 관찰될 시 풍선유도도관을 같이 사용하는 것은 매우 도움 이 될 수 있다(37).

\section{결론}

제2세대 회수성스텐트의 도입으로 증명된 혈전제거술의 유용성은 다양한 후향적 임상시험들뿐 만 아니라 여러 차례의 무작위 배정 임상시험에서도 입증되었다. 현재 전방순환동맥 폐쇄로 인한 급성 허혈성 뇌졸중의 치료에 있어 고식적인 치료에 비해 우월성이 입증된 유일한 치료로서 이미 전 세계적으로 모든 진료지침에서 적극적으로 권장되고 있다.

최근에는 발달된 다중영상기법을 통한 뇌관류영상의 분석에 힘입어 기존의 기준이었던 발생 후 6시간을 넘어서는 환자군에서도 혈전제거술의 유용성이 입증되었으며, 이로 인해 급성 허혈성 뇌 졸중 환자 치료에 새로운 전기를 만들어가고 있다. 또한, 아직 무작위 배정 임상시험으로 입증되 지 않았지만, 후방 순환계 혈관 폐색, 원위부 혈관 폐색 등에 대한 효과에 대한 보고도 점차 증가되 고 있다(43).

앞으로 현재 진행 중인 무작위 배정 임상시험들의 결과가 추가적으로 발표되고, 새로운 혈전제 거기구와 개발 시술법의 개선 등과 맞물려, 혈전제거술의 치료 효과는 더욱 향상될 것으로 기대될 뿐만 아니라 적용 가능 시간(time window)도 발생 후 24시간 이상으로 확장될 것으로 예상된다.

\section{Author Contributions}

Conceptualization, K.B.M.; investigation, all authors; supervision, K.B.M.; validation, all authors; visualization, all authors; writing-original draft, K.J.H.; and writing-review \& editing, K.B.M.

\section{Conflicts of Interest}

The authors have no potential conflicts of interest to disclose.

\section{REFERENCES}

1. Lindsay MP, Norrving B, Sacco RL, Brainin M, Hacke W, Martins S, et al. World Stroke Organization (WSO): global stroke fact sheet 2019. Int J Stroke 2019;14:806-817

2. Kim JY, Kang K, Kang J, Koo J, Kim DH, Kim BJ, et al. Executive summary of stroke statistics in Korea 2018: a report from the epidemiology research council of the Korean Stroke Society. J Stroke 2019;21:42-59

3. Khatri P, Abruzzo T, Yeatts SD, Nichols C, Broderick JP, Tomsick TA; IMS I and II Investigators. Good clinical outcome after ischemic stroke with successful revascularization is time-dependent. Neurology 2009;73:1066-1072

4. Lee KY, Han SW, Kim SH, Nam HS, Ahn SW, Kim DJ, et al. Early recanalization after intravenous administration of recombinant tissue plasminogen activator as assessed by pre- and post-thrombolytic angiography in acute ischemic stroke patients. Stroke 2007;38:192-193

5. Broderick JP, Palesch YY, Demchuk AM, Yeatts SD, Khatri P, Hill MD, et al. Endovascular therapy after intravenous t-PA versus t-PA alone for stroke. N Engl J Med 2013;368:893-903

6. Ciccone A, Valvassori L, Nichelatti M, Sgoifo A, Ponzio M, Sterzi R, et al. Endovascular treatment for acute 
ischemic stroke. N Engl J Med 2013;368:904-913

7. Kidwell CS, Jahan R, Gornbein J, Alger JR, Nenov V, Ajani Z, et al. A trial of imaging selection and endovascular treatment for ischemic stroke. N Engl J Med 2013;368:914-923

8. Saver JL, Jahan R, Levy El, Jovin TG, Baxter B, Nogueira RG, et al. Solitaire flow restoration device versus the Merci Retriever in patients with acute ischaemic stroke (SWIFT): a randomised, parallel-group, non-inferiority trial. Lancet 2012;380:1241-1249

9. Nogueira RG, Lutsep HL, Gupta R, Jovin TG, Albers GW, Walker GA, et al. Trevo versus Merci retrievers for thrombectomy revascularisation of large vessel occlusions in acute ischaemic stroke (TREVO 2): a randomised trial. Lancet 2012;380:1231-1240

10. Berkhemer OA, Fransen PS, Beumer D, Van den Berg LA, Lingsma HF, Yoo AJ, et al. A randomized trial of intraarterial treatment for acute ischemic stroke. N Engl J Med 2015;372:11-20

11. Goyal M, Demchuk AM, Menon BK, Eesa M, Rempel JL, Thornton J, et al. Randomized assessment of rapid endovascular treatment of ischemic stroke. N Engl J Med 2015;372:1019-1030

12. Saver JL, Goyal M, Bonafe A, Diener HC, Levy El, Pereira VM, et al. Stent-retriever thrombectomy after intravenous t-PA vs. t-PA alone in stroke. N Engl J Med 2015;372:2285-2295

13. Campbell BC, Mitchell PJ, Kleinig TJ, Dewey HM, Churilov L, Yassi N, et al. Endovascular therapy for ischemic stroke with perfusion-imaging selection. N Engl J Med 2015;372:1009-1018

14. Jovin TG, Chamorro A, Cobo E, De Miquel MA, Molina CA, Rovira A, et al. Thrombectomy within 8 hours after symptom onset in ischemic stroke. N Engl J Med 2015;372:2296-2306

15. Powers WJ, Derdeyn CP, Biller J, Coffey CS, Hoh BL, Jauch EC, et al. 2015 American Heart Association/American Stroke Association focused update of the 2013 guidelines for the early management of patients with acute ischemic stroke regarding endovascular treatment: a guideline for healthcare professionals from the American Heart Association/American Stroke Association. Stroke 2015;46:3020-3035

16. Hong KS, Ko SB, Yu KH, Jung C, Park SQ, Kim BM, et al. Update of the Korean clinicl practice guidelines for endovascular recanalization therapy in patients with acute ischemic stroke. J Stroke 2016;18:103-113

17. Saver JL, Goyal M, Van der Lugt A, Menon BK, Majoie CB, Dippel DW, et al. Time to treatment with endovascular thrombectomy and outcomes from ischemic stroke: a meta-analysis. JAMA 2016;316:1279-1288

18. Lansberg MG, Cereda CW, Mlynash M, Mishra NK, Inoue M, Kemp S, et al. Response to endovascular reperfusion is not time-dependent in patients with salvageable tissue. Neurology 2015;85:708-714

19. Lansberg MG, Straka M, Kemp S, Mlynash M, Wechsler LR, Jovin TG, et al. MRI profile and response to endovascular reperfusion after stroke (DEFUSE 2): a prospective cohort study. Lancet Neurol 2012;11:860-867

20. Ribo M, Flores A, Rubiera M, Pagola J, Sargento-Freitas J, Rodriguez-Luna D, et al. Extending the time window for endovascular procedures according to collateral pial circulation. Stroke 2011;42:3465-3469

21. Nogueira RG, Jadhav AP, Haussen DC, Bonafe A, Budzik RF, Bhuva P, et al. Thrombectomy 6 to 24 hours after stroke with a mismatch between deficit and infarct. N Engl J Med 2018;378:11-21

22. Albers GW, Marks MP, Kemp S, Christensen S, Tsai JP, Ortega-Gutierrez S, et al. Thrombectomy for stroke at 6 to 16 hours with selection by perfusion imaging. N Engl J Med 2018;378:708-718

23. Ko SB, Park HK, Kim BM, Heo JH, Rha JH, Kwon SU, et al. 2019 update of the Korean clinical practice guidelines of stroke for endovascular recanalization therapy in patients with acute ischemic stroke. Neurointervention 2019;14:71-81

24. Singer OC, Berkefeld J, Nolte CH, Bohner G, Haring HP, Trenkler J, et al. Mechanical recanalization in basilar artery occlusion: the ENDOSTROKE study. Ann Neurol 2015;77:415-424

25. Phan K, Phan S, Huo YR, Jia F, Mortimer A. Outcomes of endovascular treatment of basilar artery occlusion in the stent retriever era: a systematic review and meta-analysis. J Neurointerv Surg 2016;8:1107-1115

26. Lindsberg PJ, Mattle HP. Therapy of basilar artery occlusion: a systematic analysis comparing intra-arterial and intravenous thrombolysis. Stroke 2006;37:922-928

27. Kim DH, Kim B, Jung C, Nam HS, Lee JS, Kim JW, et al. Consensus statement by Korean Society of Interventional Neuroradiology and Korean Stroke Society: hyperacute endovascular treatment workflow to reduce door-to-reperfusion time. Korean J Radiol 2018;19:838-848

28. Kim BM. Stent retriever (Stentriever) thrombectomy for acute ischemic stroke. In Park J, ed. Acute ischemic stroke. Singapore: Springer 2017:191-211

29. Zaidat OO, Bozorgchami H, Ribó M, Saver JL, Mattle HP, Chapot R, et al. Primary results of the multicenter ARISE II study (Analysis of Revascularization in Ischemic Stroke With EmboTrap). Stroke 2018;49:1107-1115 
30. Mokin M, Setlur Nagesh SV, Ionita CN, Mocco J, Siddiqui AH. Stent retriever thrombectomy with the Cover accessory device versus proximal protection with a balloon guide catheter: in vitro stroke model comparison. J Neurointerv Surg 2016;8:413-417

31. Nogueira RG, Frei D, Kirmani JF, Zaidat O, Lopes D, Turk AS 3rd, et al. Safety and efficacy of a 3-dimensional stent retriever with aspiration-based thrombectomy vs aspiration-based thrombectomy alone in acute ischemic stroke intervention: a randomized clinical trial. JAMA Neurol 2018;75:304-311

32. Turk AS, Frei D, Fiorella D, Mocco J, Baxter B, Siddiqui A, et al. ADAPT FAST study: a direct aspiration first pass technique for acute stroke thrombectomy. J Neurointerv Surg 2018;10:i4-i7

33. Lapergue B, Blanc R, Gory B, Labreuche J, Duhamel A, Marnat G, et al. Effect of endovascular contact aspiration vs stent retriever on revascularization in patients with acute ischemic stroke and large vessel occlusion: the ASTER randomized clinical trial. JAMA 2017;318:443-452

34. Turk AS 3rd, Siddiqui A, Fifi JT, De Leacy RA, Fiorella DJ, Gu E, et al. Aspiration thrombectomy versus stent retriever thrombectomy as first-line approach for large vessel occlusion (COMPASS): a multicentre, randomised, open label, blinded outcome, non-inferiority trial. Lancet 2019;393:998-1008

35. Humphries W, Hoit D, Doss VT, Elijovich L, Frei D, Loy D, et al. Distal aspiration with retrievable stent assisted thrombectomy for the treatment of acute ischemic stroke. J Neurointerv Surg 2015;7:90-94

36. Wong J, Telischak N, Heit J, Moraff A, Dodd R, Do H, et al. E-083 Acute stroke intervention for large vessel occlusion with combined stent retriever and suction thrombectomy (Solumbra technique): a retrospective analysis of 85 patients. J Neurolnterv Surg 2016;8:A86

37. Leung V, Sastry A, Srivastava S, Wilcock D, Parrott A, Nayak S. Mechanical thrombectomy in acute ischaemic stroke: a review of the different techniques. Clin Radiol 2018;73:428-438

38. Kim BM. Causes and solutions of endovascular thrombectomy failure. J Stroke 2017;19:131-142

39. Nguyen TN, Malisch T, Castonguay AC, Gupta R, Sun CH, Martin CO, et al. Balloon guide catheter improves revascularization and clinical outcomes with the Solitaire device: analysis of the North American Solitaire Acute Stroke Registry. Stroke 2014;45:141-145

40. Baek JH, Kim BM, Kang DH, Heo JH, Nam HS, Kim YD, et al. Balloon guide catheter is beneficial in endovascular treatment regardless of mechanical recanalization modality. Stroke 2019;50:1490-1496

41. Kang DH, Kim BM, Heo JH, Nam HS, Kim YD, Hwang YH, et al. Effect of balloon guide catheter utilization on contact aspiration thrombectomy. J Neurosurg 2019;131:1494-1500

42. Kang DH, Kim BM, Heo JH, Nam HS, Kim YD, Hwang YH, et al. Effects of first pass recanalization on outcomes of contact aspiration thrombectomy. J Neurointerv Surg 2020;12:466-470

43. Coutinho JM, Liebeskind DS, Slater LA, Nogueira RG, Baxter BW, Levy El, et al. Mechanical thrombectomy for isolated M2 occlusions: a post hoc analysis of the STAR, SWIFT, and SWIFT PRIME studies. AJNR Am J Neuroradiol 2016;37:667-672 


\section{급성 허혈성 뇌졸중의 혈관 내 치료}

\section{김준휘 ${ }^{1} \cdot$ 김병문 ${ }^{2 *}$}

급성 허혈성 뇌졸중은 심각한 후유증이나 사망에 이르는 가장 큰 원인 질환들 중 하나이다. 제2세대 혈전제거기구가 도입된 이후로 급성 허혈성 뇌졸중에서 혈관 내 재개통 치료는 급 속히 발전해 왔고, 최근에는 표준 치료 중의 하나가 되었다. 이 종설에서는 급성 허혈성 뇌졸 중에서 혈관 내 치료와 고식적인 치료를 무작위 배정으로 비교한 임상 연구들의 결과를 간략 히 기술하고, 새로이 개정된 급성 허혈성 뇌졸중에서의 혈관 내 치료의 적응증과, 현재 혈관 내 치료에 쓰이는 기구들과 방법에 대해 알아보고자 한다.

1연세대학교 의과대학 용인세브란스병원 영상의학과,

2연세대학교 의과대학 세브란스병원 영상의학과 